\title{
Maturação fisiológica de sementes de ingazeiro (Inga striata) Benth
}

\section{Physiological maturity of ingazeiro Inga striata Benth. Seeds}

\author{
Marlene Feliciano Mata ${ }^{1 *}$; Kelina Bernardo Silva ${ }^{2}$; Riselane de Lucena Alcântara \\ Bruno $^{3}$; Leonardo Pessoa Felix ${ }^{3}$; Sebastião Medeiros Filho ${ }^{4}$; Edna Ursulino Alves ${ }^{3}$
}

\section{Resumo}

\begin{abstract}
Inga striata Benth., popularmente conhecida como ingazeiro, é uma frutífera nativa das florestas tropicais e matas ciliares da Amazônia, Nordeste e Minas Gerais. É utilizada na recuperação de solos de áreas degradadas e na arborização urbana e rural. O objetivo do trabalho foi determinar os índices mais adequados para avaliação da maturidade e o ponto ideal de colheita das sementes de I. striata Benth. As árvores de I. striata estavam em floresta de brejo de altitude no Campus II da Universidade Federal da Paraíba (UFPB), em Areia-PB. As avaliações da maturação das sementes foram realizadas em seis épocas de colheitas de frutos após a antese $(95,110,125,140,155$ e 170 DAA) e em dois anos de observações consecutivos (duas safras). O delineamento utilizado foi o inteiramente casualizado seguindo um esquema fatorial 2 x 6 (dois períodos de observação e seis épocas de colheitas dos frutos). Em cada colheita foram avaliadas as dimensões de frutos e sementes, teor de água e massa seca das sementes, bem como a germinação e o vigor (primeira contagem de germinação, índice de velocidade de germinação, comprimento e massa seca da raiz primária e parte aérea). A maturidade fisiológica das sementes foi atingida aos 146 a 166 dias após a antese no primeiro ano e aos 155 dias no segundo ano, períodos em que apresentaram o menor teor de água, máximo acúmulo de massa seca e poder germinativo; O tamanho, teor de água, massa seca da semente, capacidade germinativa e ainda a massa seca da parte aérea da plântula, foram os parâmetros que melhor determinaram a maturação fisiológica das sementes de I. striata.
\end{abstract}

Palavras-chave: Época de colheita, germinação, vigor, maturidade fisiológica

\begin{abstract}
Inga striata Benth., Popularly known as ingazeiro, is a native fruit of tropical forests and riparian forests of the Amazon, Northeast and Minas Gerais. It is used in the reclamation of degraded areas and in rural and urban forestry. The objective of this study was to determine the most appropriate indices for assessing the maturity and ideal harvest seeds I. striata Benth. Trees I. striata were in swamp forest of altitude on Campus II of the Federal University of Paraíba (UFPB), Areia-PB. Assessments of seed maturation were performed in six seasons fruit harvests after anthesis $(95,110,125,140,155$ and 170 DAA) and two consecutive years of observations (two seasons). The experimental design was completely randomized following a factorial $2 \times 6$ (two periods of observation and six seasons crop of fruit). At each harvest were evaluated dimensions of fruits and seeds, water content and dry weight of seeds and their germination and vigor (first germination, speed of germination, length and mass of the primary root and shoot). The seed physiological maturity was reached at 146 to 166 days after flowering in the first year and 155 days in the second year, in which periods had the lowest water
\end{abstract}

1 Prof Adjunta, Universidade Estadual do Vale do Acaraú, Sobral, CE. E-mail: mfm@yahoo.com.br

2 Prof $^{a}$ Adjunta, Dept ${ }^{\circ}$ de Agrárias e Exatas, Universidade Estadual da Paraíba, UEPB, Catolé do Rocha, PB. E-mail: kelinabernardo@yahoo.com.br

3 Profs. Adjunto, Dept ${ }^{\circ}$. de Fitotecnia, UFPB, CCA, Areia, PB. E-mail: lane@cca.ufpb.br; lpfelix@cca.ufpb.br; ednaursulino@ yahoo.com.br

4 Pesquisador Embrapa Algodão, Campina Grande, PB. E-mail: smfilho@hotmail.com

* Autor para correspondência 
content, maximum dry matter accumulation and germination; The size, content water, dry mass of seed germination and the dry weight of the aerial part of the seedling, were the best parameters that determined the physiological maturity of seeds of I. striata.

Key words: Harvesting time, germination, vigor, physiological maturity

\section{Introdução}

A seleção das espécies arbóreas nativas visando $o$ atendimento de programas de reflorestamento, melhoramento genético ou de silvicultura é dificultada pelo desconhecimento tanto da qualidade fisiológica das sementes como da produção de mudas (CARVALHO et al., 1980).

O estudo da maturação é uma importante forma de se conhecer o comportamento das espécies no tocante à sua reprodução, possibilitando assim, prever o estabelecimento e a época adequada de colheita. Além disso, pode-se obter material genético de boa qualidade fisiológica, que é a base para os programas de melhoramento, silviculturais, conservação genética e recuperação de áreas degradadas (FIGLIOLIA; KAGEYAMA, 1994).

Inga striata é uma arbórea nativa da família Fabaceae (Mimosoideae), de ocorrência nas florestas tropicais, matas ciliares e ambientes periodicamente inundados. Popularmente, é conhecida por ingá, ingazeira, ingá-caixão, ingá de quatro quinas ou ingábanana. Apresenta glândulas foliares (nectários), flores tubulosas com longos estames, legumes indeiscentes tetragonais, sementes com sarcotesta branca adocicada, comestível. Ocorre nas Guianas, Bolívia, Peru, Equador e Colômbia. No Brasil, é freqüente desde a Amazônia até às regiões do Nordeste, Sul e Sudeste. É utilizada na arborização, recuperação de solos de áreas degradadas e no sombreamento da cultura de café. Frequentemente inicia a floração em outubro, frutificando no final de fevereiro até junho. Pode apresentar mais de uma floração ao ano (PENNINGTON, 1997; GARCIA, 1998).

As sementes de ingá são classificadas como recalcitrantes (BILIA; BARBEDO; MARCOS FILHO, 2003), sendo altamente intolerantes à dessecação e de baixa longevidade natural (FIGLIOLIA; KAGEYAMA, 1994; PRITCHARD; HAYE; STEADMAN, 1995; BARBEDO; BILIA, 1997; BARBEDO; CÍCERO, 1998; FARIA et al., 2006). Esse tipo de semente é de grande interesse para estudos que buscam o desenvolvimento de procedimentos visando ampliar a capacidade de armazenamento em sementes recalcitrantes (CORVELLO et al., 1999; BILIA; BARBEDO; MARCOS FILHO, 2003). Neste sentido, Andréo, Nakagawa e Barbedo (2006), procuraram manter o teor de água em embriões de Inga vera Willd. subsp. affinis (DC.) T. D. Pennington por meio do armazenamento em soluções de polietileno glicol 6000 (PEG), com potencial hídrico conhecido e préestabelecido, visando prolongar a longevidade. Já Bonjovani e Barbedo, (2008) estudando sementes de Inga vera subsp. affinis por exemplo, confirmam que as mesmas são recalcitrantes, uma vez que não toleram redução do teor de água para valores inferiores a $35 \%$. Entretanto, constataram que embriões dessa espécie, embora nenhum tratamento utilizado na pesquisa tenha proporcionado resistência à temperatura de $-18^{\circ} \mathrm{C}$, a secagem dos embriões maduros a $-4 \mathrm{MPa}$ proporcionou maior tolerância à redução de temperatura até níveis de congelamento da água $\left(-2^{\circ} \mathrm{C}\right)$.

Em diferentes espécies do gênero Inga, como I. uruguensis, I. vera, I. sessilis e I. laurina, o alto porcentual germinativo e rápido desenvolvimento de suas plântulas em áreas abertas (BARBEDO; BILIA, 1997; BILIA; MARCOS-FILHO; NOVEMBRE, 1999; FARIA et al., 2006) as torna adequadas para serem utilizadas para reflorestamento, ornamentação e sombreamento das culturas de café e cacau devido a estrutura da copa.

Apesar de ser um gênero muito rico, com cerca de 300 espécies, dados relativos à fenologia e 
maturação de frutos e sementes são praticamente inexistentes. Apenas para Inga uruguensis Hook (= I. vera subsp. affinis (DC.) T.D. Pennington) foi observado que a massa seca de frutos e sementes, juntamente com a coloração dos frutos e a capacidade germinativa das sementes foram os melhores indicadores para determinar o momento ideal da colheita (FIGLIOLIA; KAGEYAMA, 1994) e, em $I$. edulis Mart. foi verificado quatro florações durante o ano, demonstrando a elasticidade dos aspectos fenológicos em espécies desse gênero (FALCÃO; CLEMENT, 2000). Para muitas espécies arbóreas tropicais, o ponto de maturidade fisiológica de frutos e sementes ainda é totalmente desconhecido, embora diversos autores revelem que o estádio de maturidade fisiológica é determinado pelo máximo de germinação e vigor, indicando o ponto ideal para a colheita (POPINIGIS, 1997; MALAVASI, 1998; CARVALHO; NAKAGAWA, 2000, MARCOSFILHO, 2005).

O processo de maturação de frutos e sementes envolve observações sobre as modificações de natureza morfológica e fisiológica desde o momento da fecundação do óvulo até a maturidade. Parâmetros como tamanho, teor de água, conteúdo da massa seca, germinação e vigor da semente, além de transformações bioquímicas, são normalmente analisados na indicação do ponto de maturidade fisiológica das sementes. Nessa época cessa a translocação de fotossintetizados e, a partir daí, ocorrem alterações fisiológicas que levam à secagem das sementes. Este ponto pode variar em função da espécie e do ambiente, tornandose necessário a definição de índices de maturação para a época adequada de colheita de sementes (AGUIAR; PIÑA-RODRIGUES; FIGLIOLIA, 1993; CARVALHO; NAKAGAWA, 2000).
As associações de diferentes índices de maturação têm sido estudadas paralelamente no sentido de permitir uma melhor avaliação do ponto de maturidade fisiológica de sementes das espécies nativas. As alterações funcionais mais estudadas são as modificações externas do fruto e da semente, variações no teor de água, vigor e acúmulo de matéria seca da semente.

Revisando a literatura pertinente, não foi encontrada nenhuma referência sobre o processo de maturação fisiológica em sementes de Inga striata, o que dificulta o desenvolvimento de programas de reflorestamento ou cultivo comercial desta espécie. O objetivo da pesquisa foi estudar o processo de maturação fisiológica de sementes de $I$. striata, a fim de determinar os índices mais adequados para avaliação da maturidade e o ponto ideal de colheita das sementes.

\section{Material e Métodos}

Área de estudo - $\mathrm{O}$ experimento de campo foi conduzido em dois anos, entre novembro de 2006 a abril de 2007 e novembro de 2007 a maio de 2008 em floresta de brejo de altitude no Campus II da Universidade Federal da Paraíba, no município de Areia. A área estudada apresenta altitude entre 550 e $580 \mathrm{~m}$, localizada aos $6^{\circ} 58^{\prime}$ de latitude sul e 35²' de longitude oeste. De acordo com a classificação de Gaussem, na área o bioclima é 3 dth nordestino sub-seco, com precipitação pluvial média anual de $1.400 \mathrm{~mm}$. Os dados climáticos de temperatura, precipitação pluviométrica, durante o período do experimento foram obtidos na estação meteorológica do Campus II da UFPB. No geral, no período de observação, as médias térmicas foram mais elevadas entre os meses de dezembro, janeiro e fevereiro e os maiores índices de pluviosidade entre março e agosto (Figura 1). 
Figura 1. Dados climáticos (temperatura e precipitação) verificados no período de condução do experimento de campo. Fonte: Estação Metereológica da Estação Experimental do CCA/UFPB.
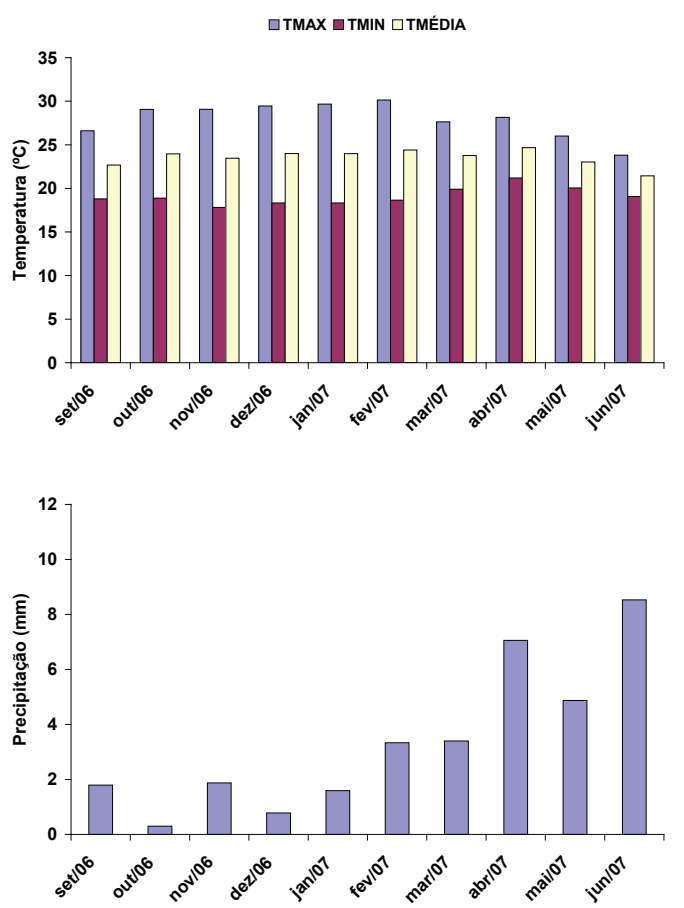

Fonte: Elaboração dos autores.

Seleção das árvores e marcação das inflorescências - Inicialmente foram selecionadas dez árvores matrizes, vigorosas e de boa aparência fitossanitária, com altura entre sete a doze metros e idade superior a dez anos. Nos dois anos do experimento, após se constatar que $50 \%$ das inflorescências encontravam-se em antese, procedeu-se a marcação em média de 30 inflorescências, utilizando-se fios de lã colorida (Figura 2 A).

Colheita de frutos e sementes - As colheitas dos frutos foram realizadas quinzenalmente, entre 22 de janeiro a 25 de abril de 2007 e, 19 de fevereiro a 05 de maio de 2008, iniciadas aos 95 dias após a antese, quando as sementes se encontravam
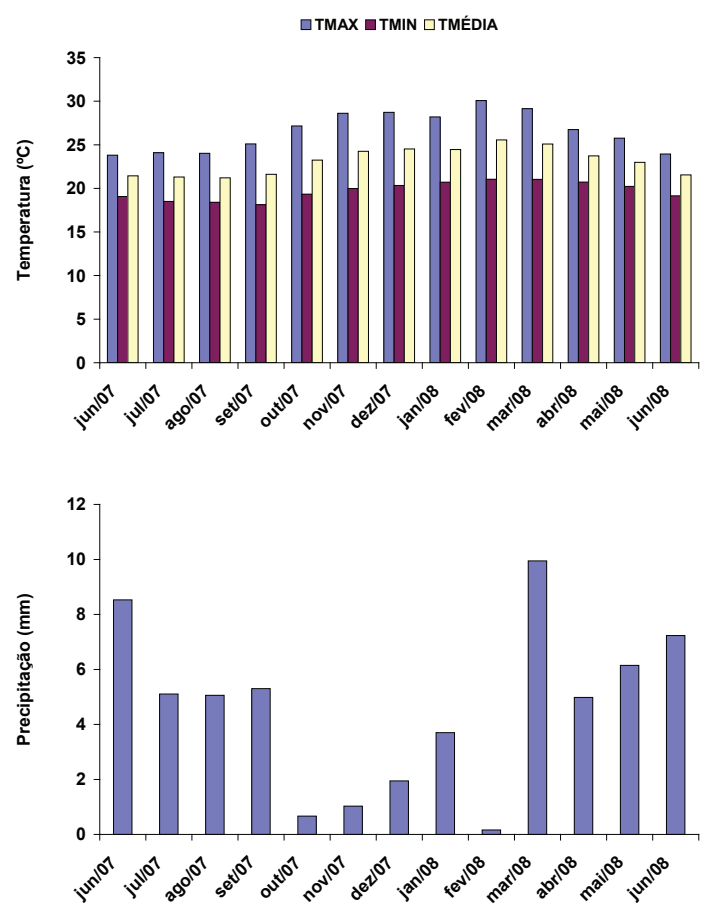

formadas e estenderam-se até os 170 dias. Foram coletados frutos e sementes aos 95 (Figura 2 B e C), 110 (Figura D e E), 125 (Figura F e G), 140 (Figura H e I) 155 (Figura J) e 170 dias após a antese (Figura $\mathrm{K}$ e L), além de frutos caídos, o que ocorreu a partir dos 140 dias da antese. Após cada colheita, as amostras foram acondicionadas em embalagens de plástico, para evitar alterações no teor de água e, em seguida encaminhadas ao Laboratório de Análise de Sementes do Centro de Ciências Agrárias do CCA, da Universidade Federal da Paraíba. Posteriormente as sementes foram retiradas dos frutos e a sarcotesta foi removida manualmente. Imediatamente após o beneficiamento foram realizadas as determinações descritas a seguir. 
Figura 2. Estádios de maturação das sementes em Inga striata, observados em 2007 e 2008. A. Marcação das flores em antese; B. Fruto jovem, verde-intenso e flexível-95 DAA; C. Sementes jovens com sarcotesta aos 95 DAA; D. Fruto verde aos 110 DAA; E. sementes despolpadas de frutos verdes aos 110 DAA; F. Frutos verdes aos 125 DAA; G. Sementes despolpadas 125 DAA; H. Frutos verde-amarelado aos 140 DAA; I. Sementes maduras aos 140 DAA; J. Frutos amarelos colhidos do chão aos 155 DAA; K. Frutos amarelos aos 170 DAA; L. Sementes maduras aos 170 DAA.
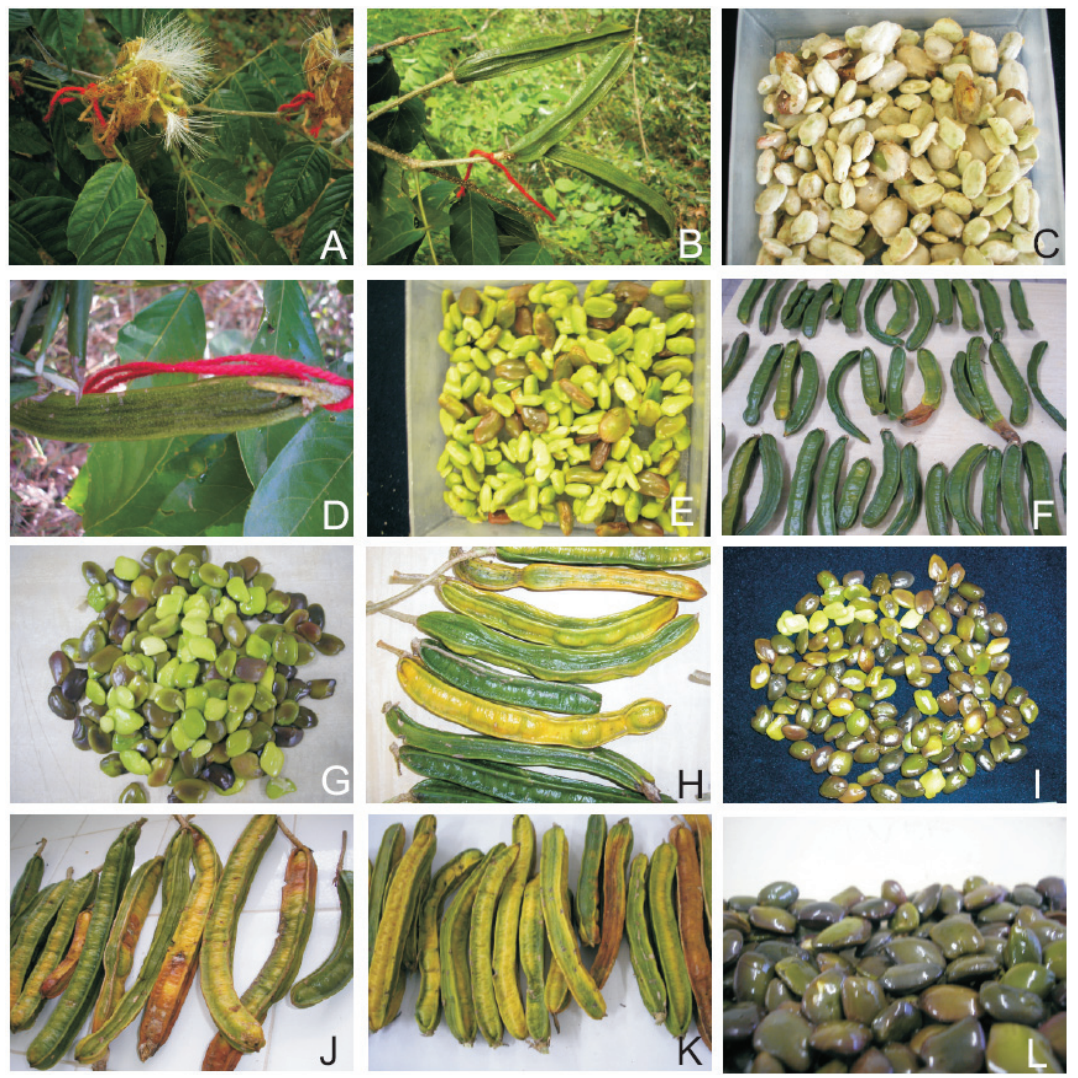

Fonte: Elaboração dos autores.

Análises fisicas

Dimensões de frutos e sementes - foram tomadas quinzenalmente com o auxílio de um paquímetro digital em 100 frutos e 100 sementes, logo após cada colheita. Além disso, foi feita a determinação do número de sementes por fruto.

Teor de água das sementes - foi determinado quinzenalmente, pelo método da estufa a $105 \pm 3^{\circ} \mathrm{C}$ durante 24 horas. Foram utilizadas quatro amostras de vinte sementes para cada época de colheita e as sementes pesadas em balança analítica com precisão de $0,001 \mathrm{~g}$. Os resultados foram expressos em porcentagens com base no peso úmido das sementes, conforme as Regras para Análise de Sementes (BRASIL, 2009).
Massa seca das sementes e frutos - foi calculada após a determinação do teor de água, em todas as amostras de dez frutos, que inicialmente foram secos em estufa de ventilação forçada, a $80^{\circ} \mathrm{C}$ durante 48 horas e, em seguida, pesados.

\section{Análises fisiológicas}

Teste de germinação - os testes de germinação foram realizados utilizando-se rolos de papel germitest, umedecidos com água destilada na proporção de 2,5 vezes o peso seco do papel. As sementes foram mantidas em germinador a temperatura constante de $30^{\circ} \mathrm{C}$ durante 30 dias, utilizando-se quatro repetições de 25 sementes para cada período de colheita. Nas avaliações utilizou-se 
como critério para germinação, a emissão da raiz primária e da parte aérea, observadas dos sete aos vinte dias após a semeadura adotado por Barbedo e Cícero, (1998) em sementes de I. uruguensis.

Primeira contagem de germinação - realizada no sétimo dia após a semeadura, onde foi computada a porcentagem de plântulas normais adotandose o critério utilizado na germinação de sementes de I. uruguensis (BILIA; MARCOS FILHO; NOVEMBRE, 1998).

Índice de velocidade de germinação - este experimento foi conduzido junto ao teste de germinação, sendo feitas contagens diárias das sementes com pelo menos $2 \mathrm{~cm}$ de protrusão da radícula (MAGUIRE, 1962).

Comprimento da raiz primária e parte aérea ao final do teste de germinação as plântulas normais de cada repetição foram medidas, e calculado o comprimento da raiz primária e da parte aérea.

Massa seca do sistema radicular e da parte aérea - após as medições, o sistema radicular e a parte aérea das plântulas foram separados e colocados em sacos de papel e, em seguida, submetidos à estufa com circulação de ar a $65^{\circ} \mathrm{C}$ por 48 horas. Decorrido esse período, o material foi pesado em balança analítica (VIEIRA; CARVALHO, 1994).

Análise estatística - $\mathrm{O}$ delineamento estatístico utilizado foi inteiramente casualizado e, os dados foram submetidos à análise de variância e de regressão polinomial, em função das cinco épocas de colheita para os dois anos de experimento. A análise foi realizada separadamente por coloração do fruto, visto que frutos de coloração verde ocorreram em todas as colheitas e de outras colorações, ocorreram apenas a partir dos 140 dias após a antese.

\section{Resultados}

Dados fenológicos e reprodutivos - Em meados de outubro de 2007 e novembro de 2008 foi registrado intenso florescimento e queda de flores, o que ocorreu de maneira mais ou menos sincrônica nos dez indivíduos estudados. As inflorescências individualmente apresentaram numerosas flores em distintos estádios de desenvolvimento. Foram observados na mesma inflorescência flores em botão, em início de antese, em antese e em senescência. Este fato possibilitou a formação paralela de frutos em diferentes estádios de desenvolvimento. Em alguns indivíduos estudados, foi observada uma segunda floração ao final do período de observação, sugerindo que na região estudada a espécie poderáapresentar dois períodos de florescimento e frutificação. Observações similares foram obtidas na maturação e fenologia de Inga uruguensis Hook. et Arn (FIGLIOLIA; KAGEYAMA, 1994) e, apesar de algumas árvores apresentarem o florescimento em diferentes estádios, a evolução dos processos de desenvolvimento das flores e dos frutos foram parcialmente sincrônicos entre os indivíduos observados.

Durante o ano de 2007, observou-se apenas ocorrência de frutos de coloração verde até os $125^{\circ}$ dia após a antese, e a partir do $140^{\circ}$ iniciou o aparecimento de frutos amarelados, amarelos e senescentes, enquanto no ano de 2008, esse estágio fenológico foi atingido já a partir do $125^{\circ}$ DAA. No estádio de frutos amarelos e dispersos ocorreu intensa infestação de larvas na sarcotesta adocicada (Figura 3).

Figura 3. Infestação de larvas em frutos amarelos.

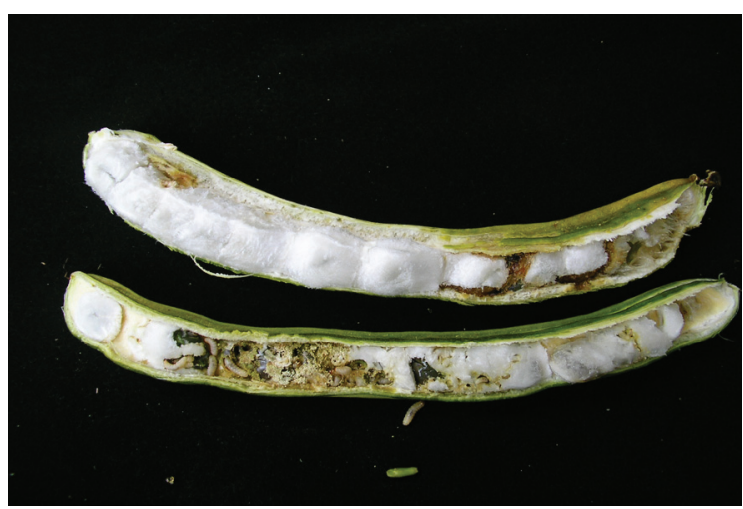

Fonte: Elaboração dos autores. 
Para o período de 2007, os valores máximos estimados de comprimento $(1,55 \mathrm{~cm})$, largura $(1,064 \mathrm{~cm})$ e espessura $(0,53 \mathrm{~cm})$ das sementes (Tabela 2) foram alcançados aos 140 e 155 dias após a antese, respectivamente. No ano de 2008 (Tabela 4), o tamanho máximo estimado das sementes (1,62, 1,12 e $0,52 \mathrm{~cm}$ de comprimento, largura e espessura, respectivamente) ocorreu aos 170 dias após a antese. Durante o processo de maturação, apesar de haver uma maior uniformidade no tamanho das sementes, durante os dois anos de estudo, observou-se uma tendência ao alcance da maturidade em períodos diferentes nos dois anos distintos. Concomitantemente, no período de 2007, o teor de água das sementes (Figura 6 A1 e A2) decresceu gradativamente até atingir o valor mínimo (46,5\%) aos 170 DAA, enquanto que o valor máximo estimado de massa seca da semente (2,50g) foi obtido aos 166 DAA. Em 2008 (Figura 6 B1 e B2) tanto o teor de água mínimo $(45,49 \%)$ como o maior valor estimado da massa seca foram alcançados aos 155 dias após a antese.

Em 2007, a germinação de sementes de I. striata (Figura 5 A1) oriundas de frutos verdes aumentou conforme a curva de regressão, alcançando valores máximos (100\%) aos 146 dias após a antese. Do mesmo modo verificou-se aumento gradativo da germinação na primeira contagem (Figura 5 A2) e IVE (Figura 6 A3) com os períodos de maturação, alcançando valores máximos $(96 \%$ e 4,5) aos 145 e 152 dias após a colheita, respectivamente. Porém, os valores máximos do comprimento da parte aérea $(9,07 \mathrm{~cm})$ (Figura 6 A4) e da raiz primária de plântulas $(17,4 \mathrm{~cm})$ (Figura 6 A5) ocorreram aos 160 e 162 dias após a antese. Entretanto, observado (Figura 6 A1 e A2) que o valor mínimo do teor de água ocorreu aos 170 dias e o máximo valor de massa seca da semente aos 166 dias após a antese.
Pode-se inferir com esses dados que o ponto de maturidade das sementes ocorre entre 146 e 166 dias após a antese, embora o menor teor de água tenha ocorrido quatro dias depois.

\section{Avaliações físicas}

Biometria de frutos e sementes, teor de água e massa seca de sementes - Os valores médios para comprimento foram maiores aos 140 dias no ano de 2007 e aos 155 dias no ano de 2008 enquanto a largura foi maior aos 140 DAA no primeiro ano e aos 170 dias no segundo. Para espessura, em 2007, os maiores valores foram observados aos 155 dias e aos 170 em 2008 (Tabelas 1e 3). Já a variação relativa ao número médio de sementes por fruto foi maior aos 170 dias no primeiro ano e 155 dias no segundo, sendo, porém em maior número no ano de 2008. Foi observado que o comprimento máximo e largura das sementes ocorreram aos 140 dias, enquanto a maior espessura se deu aos 170 dias. No segundo ano, o comprimento máximo foi atingido aos 140 DAA, e as maiores larguras e espessuras, aos 170 dias (Tabelas 2 e 4).

Com relação ao teor de água das sementes, no período de 2007, houve redução linear ao longo dos períodos de avaliação (Figura 4 A1) e em 2008 os dados se ajustaram ao modelo quadrático, com valor mínimo (45\%) aos 150 DAA e máximo aos 95 (Figura 4 B1). A massa seca da semente, no período de 2007, apresentou um comportamento quadrático, com valor máximo obtidos aos 166 DAA (Figura 4 A2), enquanto no ano seguinte, os dados não se ajustaram ao modelo de regressão e os maiores valores foram observados aos 155 dias (Figura 4 B2). No período em que as sementes estavam com o máximo conteúdo de massa seca, os frutos estavam totalmente amarelos (Figura $2 \mathrm{~J}$ ). 
Figura 4. Determinações físicas de sementes de Inga striata oriundas de frutos verdes obtidos em 2007 (A) e 2008 (B). A1, B1 - teor de umidade das sementes; A2, B2 - massa seca das sementes.
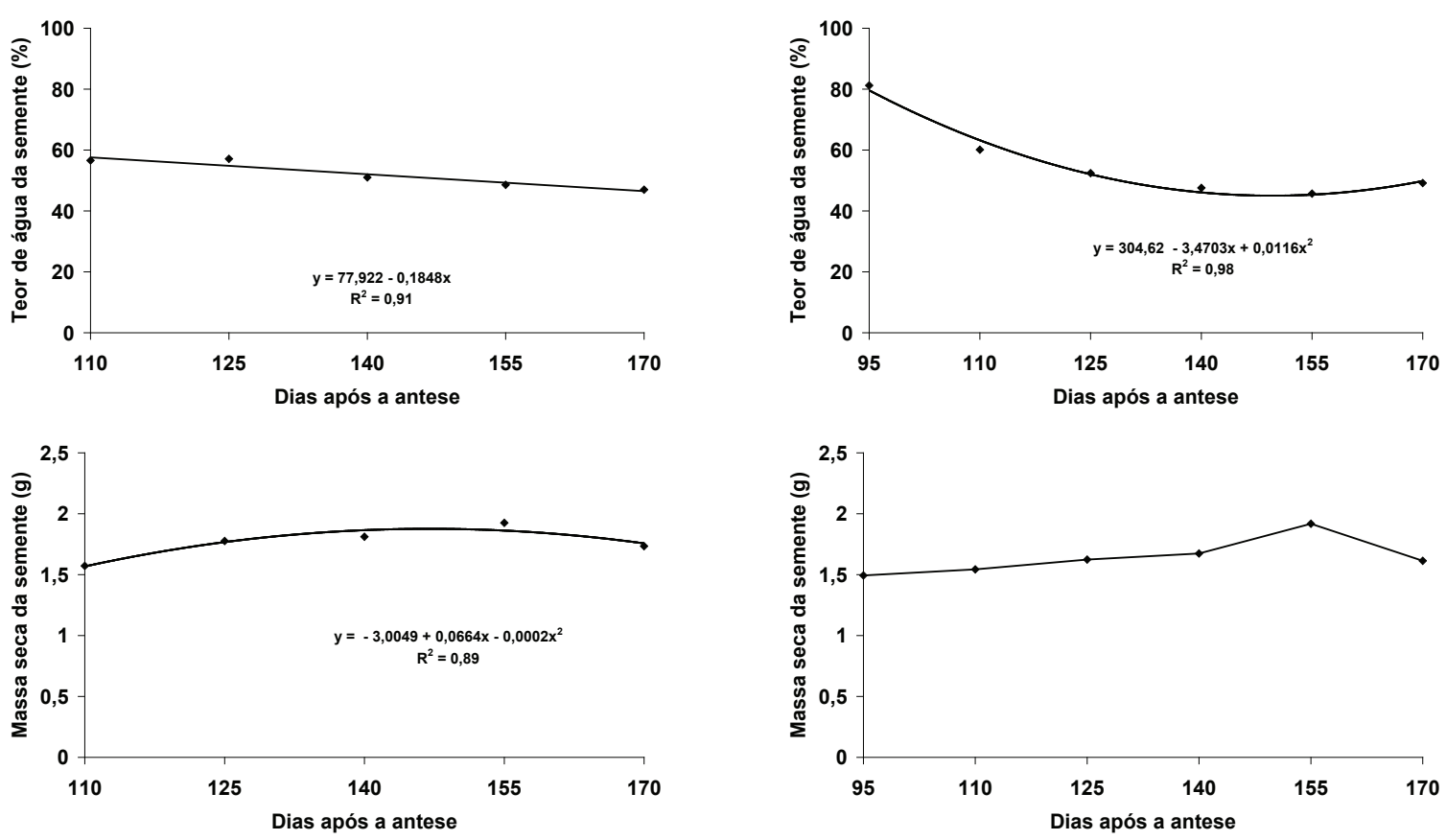

Fonte: Elaboração dos autores.

\section{Avaliações fisiológicas}

Teor de água - Os teores de água das sementes originadas dos frutos verdes (Figura 4 A1 e B1) para os dois anos de maturação são elevados na fase inicial de desenvolvimento, diminuindo gradativamente, com uma pequena variação durante o processo de maturação. Entretanto, as sementes tenderam a perder umidade à medida que amadureceram, variando de $60 \%$ aos 110 dias a $50 \%$ aos 170 dias no primeiro ano e, de $80 \%$ aos 95 dias a $58 \%$ aos 140 dias, chegando aos $50 \%$ aos 170 dias no segundo ano.

Germinação e vigor das sementes - As sementes tiveram percentual zero de germinação aos 95 dias nos dois anos do experimento e, por esta razão esse dado foi omitido na análise de regressão. No primeiro ano, os dados de germinação ajustaram-se ao modelo quadrático de regressão, com menores valores aos 110 DAA, maior percentagem de germinação aos 146 DAA com um valor máximo de $100 \%$, e, tendo mantido um poder germinativo ainda elevado, em torno de $82 \%$, aos 170 dias (Figura 5 A1). No ano seguinte os dados dessa variável não se ajustaram ao modelo de regressão (Figura 5 B1), com percentual inicial de $80 \%$ aos 110 dias, elevando-se a um valor máximo de $100 \%$ aos 125 dias e, em seguida, variando bastante ao longo de todo o período de observação. 
Figura 5. Germinação de sementes de frutos verdes e primeira contagem de Inga striata obtidos em 2007 (A) e 2008 (B). A1, B1 - germinação; A2, B2 - primeira contagem de germinação.
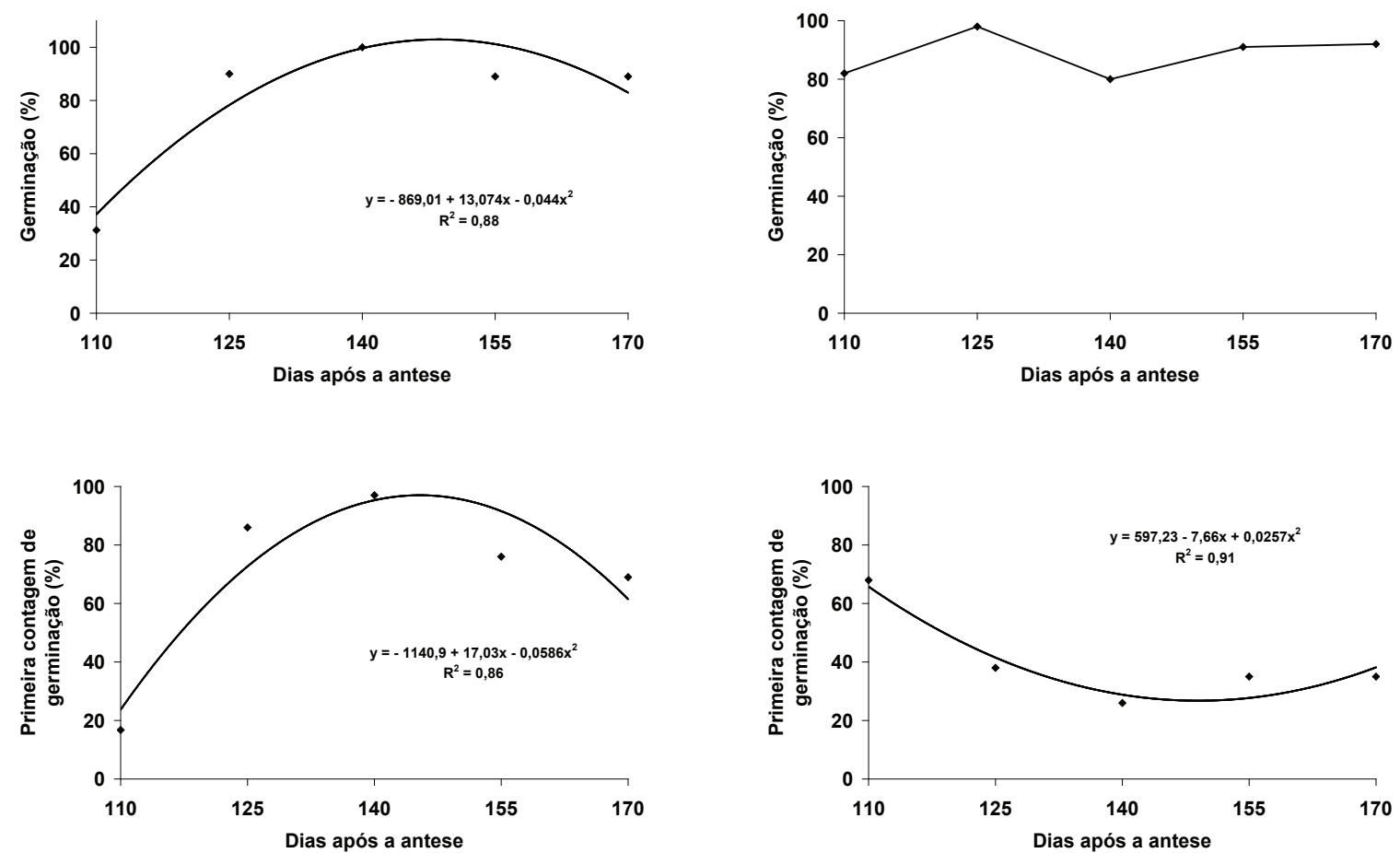

Fonte: Elaboração dos autores.

No período de 2008, embora os dados do percentual germinativo (Figura 5 B1) não tenham se ajustado a modelos de regressão observa-se variação durante o período de maturação, com elevados percentuais aos 125 dias após a antese, seguido de decréscimos e, posterior aumento aos 170 dias. O vigor das sementes, medido pela primeira contagem de germinação (Figura 5 B2) se comportou diferente da germinação, alcançando o máximo aos 110 dias após ano início do desenvolvimento. Entretanto, o índice de velocidade de germinação (IVG) (Figura 6 B3) atingiu o máximo aos 140 dias, enquanto que os valores máximos da parte aérea (Figura 6 B4) e da raiz das plântulas (Figura 6 B5) foram atingidos aos 147 e 153 dias após a antese. 
Tabela 1. Valores médios do comprimento, largura, espessura do fruto e número de sementes/fruto de Inga striata, em diferentes épocas de colheita. Areia - PB, 2007.

\begin{tabular}{|c|c|c|c|c|c|c|c|c|c|c|c|c|}
\hline \multicolumn{13}{|c|}{ FRUTO } \\
\hline \multirow{2}{*}{$\begin{array}{l}\text { Dias } \\
\text { após a } \\
\text { antese }\end{array}$} & \multicolumn{3}{|c|}{ Comprimento $(\mathrm{cm})$} & \multicolumn{3}{|c|}{ Largura $(\mathrm{cm})$} & \multicolumn{3}{|c|}{ Espessura $(\mathrm{cm})$} & \multicolumn{3}{|c|}{ № de sementes/fruto } \\
\hline & Média & $\begin{array}{l}\text { Desvio } \\
\text { Padrão }\end{array}$ & $\begin{array}{l}\mathrm{CV} \\
(\%)\end{array}$ & Média & $\begin{array}{l}\text { Desvio } \\
\text { Padrão }\end{array}$ & $\begin{array}{l}\mathrm{CV} \\
(\%)\end{array}$ & Média & $\begin{array}{l}\text { Desvio } \\
\text { Padrão }\end{array}$ & $\begin{array}{l}\mathrm{CV} \\
(\%)\end{array}$ & Média & $\begin{array}{l}\text { Desvio } \\
\text { Padrão }\end{array}$ & $\begin{array}{l}\mathrm{CV} \\
(\%)\end{array}$ \\
\hline & \multicolumn{12}{|c|}{2007} \\
\hline 95 & 16,12 & 3,74 & 23,23 & 1,340 & 1,69 & 12,66 & 1,000 & 0,44 & 44,08 & 0,00 & 0,00 & 0,00 \\
\hline 110 & 16,14 & 4,32 & 26,76 & 1,697 & 3,75 & 22,09 & 1,497 & 1,629 & 108,78 & 11,51 & 3,60 & 31,28 \\
\hline 125 & 17,33 & 4,01 & 23,11 & 1,891 & 5,01 & 26,51 & 1,269 & 0,449 & 35,39 & 10,99 & 3,35 & 30,51 \\
\hline 140 & 18,58 & 4,53 & 24,41 & 1,688 & 4,22 & 25,00 & 1,152 & 0,417 & 36,19 & 10,11 & 4,24 & 41,92 \\
\hline 155 & 16,93 & 3,62 & 21,36 & 2,186 & 2,12 & 9,71 & 1,820 & 0,398 & 21,87 & 9,55 & 3,93 & 41,16 \\
\hline 170 & 18,09 & 3,97 & 21,97 & 2,049 & 1,63 & 7,97 & 1,784 & 0,241 & 13,49 & 15,55 & 4,63 & 29,81 \\
\hline
\end{tabular}

Fonte: Elaboração dos autores.

Tabela 2. Valores médios do comprimento, largura e espessura de sementes de Inga striata, em diferentes épocas de colheita. Areia - PB, 2007.

\begin{tabular}{|c|c|c|c|c|c|c|c|c|c|}
\hline \multicolumn{10}{|c|}{ SEMENTE } \\
\hline \multirow[b]{2}{*}{$\begin{array}{l}\text { Dias após } \\
\text { a antese }\end{array}$} & \multicolumn{3}{|c|}{ Comprimento $(\mathrm{cm})$} & \multicolumn{3}{|c|}{ Largura $(\mathrm{cm})$} & \multicolumn{3}{|c|}{ Espessura $(\mathrm{cm})$} \\
\hline & Média & $\begin{array}{l}\text { Desvio } \\
\text { Padrão }\end{array}$ & CV $(\%)$ & Média & $\begin{array}{l}\text { Desvio } \\
\text { Padrão }\end{array}$ & $\mathrm{CV}(\%)$ & Média & $\begin{array}{l}\text { Desvio } \\
\text { Padrão }\end{array}$ & $\mathrm{CV}(\%)$ \\
\hline & \multicolumn{9}{|c|}{2007} \\
\hline 95 & 0,000 & 0,00 & 0,00 & 0,000 & 0,00 & 0,000 & 0,000 & 0,00 & 0,00 \\
\hline 110 & 0,745 & 1,78 & 23,88 & 0,491 & 1,50 & 30,65 & 0,164 & 1,51 & 92,20 \\
\hline 125 & 1,407 & 1,14 & 8,07 & 0,947 & 1,08 & 11,38 & 0,367 & 0,42 & 11,44 \\
\hline 140 & 1,552 & 1,99 & 12,80 & 1,064 & 1,13 & 10,65 & 0,520 & 0,54 & 10,41 \\
\hline 155 & 0,587 & 1,59 & 27,07 & 0,201 & 1,27 & 63,12 & 0,257 & 0,68 & 26,34 \\
\hline 170 & 1,492 & 1,39 & 9,32 & 0,148 & 1,28 & 12,20 & 0,534 & 0,56 & 10,41 \\
\hline
\end{tabular}

Fonte: Elaboração dos autores.

Tabela 3. Valores médios do comprimento, largura, espessura do fruto e número de sementes/fruto de Inga striata, em diferentes época de colheita. Areia - PB, 2008.

\begin{tabular}{|c|c|c|c|c|c|c|c|c|c|c|c|c|}
\hline \multicolumn{13}{|c|}{ FRUTO } \\
\hline \multirow{2}{*}{$\begin{array}{l}\text { Dias } \\
\text { após a } \\
\text { antese }\end{array}$} & \multicolumn{3}{|c|}{ Comprimento $(\mathrm{cm})$} & \multicolumn{3}{|c|}{ Largura $(\mathrm{cm})$} & \multicolumn{3}{|c|}{ Espessura $(\mathrm{cm})$} & \multicolumn{3}{|c|}{ № de sementes por fruto } \\
\hline & Média & $\begin{array}{l}\text { Desvio } \\
\text { Padrão }\end{array}$ & $\begin{array}{l}\mathrm{CV} \\
(\%)\end{array}$ & Média & $\begin{array}{l}\text { Desvio } \\
\text { Padrão }\end{array}$ & $\begin{array}{l}\text { CV } \\
(\%)\end{array}$ & Média & $\begin{array}{l}\text { Desvio } \\
\text { Padrão }\end{array}$ & $\begin{array}{l}\text { CV } \\
(\%)\end{array}$ & Média & $\begin{array}{l}\text { Desvio } \\
\text { Padrão }\end{array}$ & $\begin{array}{l}\mathrm{CV} \\
(\%)\end{array}$ \\
\hline & \multicolumn{12}{|c|}{2008} \\
\hline 95 & 20,44 & 3,82 & 18,69 & 1,782 & 3,62 & 20,31 & 1,315 & 2,88 & 21,90 & 10,42 & 1,63 & 15,64 \\
\hline 110 & 21,11 & 4,36 & 20,65 & 2,078 & 2,59 & 12,46 & 1,440 & 3,14 & 21,81 & 10,46 & 2,74 & 26,20 \\
\hline 125 & 16,60 & 3,29 & 19,82 & 2,404 & 2,15 & 8,90 & 1,713 & 2,61 & 15,24 & 12,82 & 4,00 & 31,20 \\
\hline 140 & 18,32 & 4,74 & 25,87 & 2,155 & 4,17 & 19,35 & 1,701 & 4,22 & 24,81 & 16,33 & 6,75 & 41,33 \\
\hline 155 & 22,00 & 5,27 & 23,95 & 1,878 & 6,11 & 33,00 & 1,772 & 6,68 & 37,70 & 16,33 & 6,75 & 41,33 \\
\hline 170 & 20,99 & 4,84 & 23,01 & 2,496 & 1,73 & 6,90 & 2,110 & 2,38 & 11,28 & 13,22 & 4,02 & 30,41 \\
\hline
\end{tabular}

Fonte: Elaboração dos autores. 
Tabela 4. Valores médios do comprimento, largura e espessura de semente de Inga striata, em diferentes época de colheita. Areia - PB, 2008.

\begin{tabular}{|c|c|c|c|c|c|c|c|c|c|}
\hline \multicolumn{10}{|c|}{ SEMENTE } \\
\hline \multirow{2}{*}{$\begin{array}{l}\text { Dias após } \\
\text { a antese }\end{array}$} & \multicolumn{3}{|c|}{ Comprimento $(\mathrm{cm})$} & \multicolumn{3}{|c|}{ Largura $(\mathrm{cm})$} & \multicolumn{3}{|c|}{ Espessura (cm) } \\
\hline & Média & $\begin{array}{l}\text { Desvio } \\
\text { Padrão }\end{array}$ & $\mathrm{CV}(\%)$ & Média & $\begin{array}{l}\text { Desvio } \\
\text { Padrão }\end{array}$ & CV $(\%)$ & Média & $\begin{array}{l}\text { Desvio } \\
\text { Padrão }\end{array}$ & CV (\%) \\
\hline & \multicolumn{9}{|c|}{2008} \\
\hline 95 & 0,780 & 2,23 & 28,59 & 0,355 & 2,48 & 69,97 & 0,229 & 0,70 & 30,59 \\
\hline 110 & 1,250 & 1,61 & 12,88 & 0,881 & 1,14 & 12,99 & 0,339 & 0,88 & 25,95 \\
\hline 125 & 1,459 & 1,28 & 8,77 & 0,993 & 1,03 & 10,39 & 0,452 & 1,05 & 23,26 \\
\hline 140 & 1,628 & 1,05 & 6,45 & 1,099 & 0,85 & 7,69 & 0,504 & 0,44 & 8,75 \\
\hline 155 & 1,499 & 1,18 & 7,87 & 1,019 & 1,32 & 12,99 & 0,505 & 0,70 & 13,94 \\
\hline 170 & 1,642 & 1,29 & 7,86 & 1,123 & 0,97 & 8,61 & 0,528 & 0,38 & 7,20 \\
\hline
\end{tabular}

Fonte: Elaboração dos autores.

Figura 6. Vigor de sementes oriundas de fruto verde de Inga striata obtidos em 2007 (A) e 2008 (B). A1, B1 - massa seca da parte aérea; A2, B2 - massa seca das raízes. A3, B3 - índice de velocidade de germinação (IVG); A4, B4 comprimento da parte aérea; A5, B5 - comprimento da raiz primária.
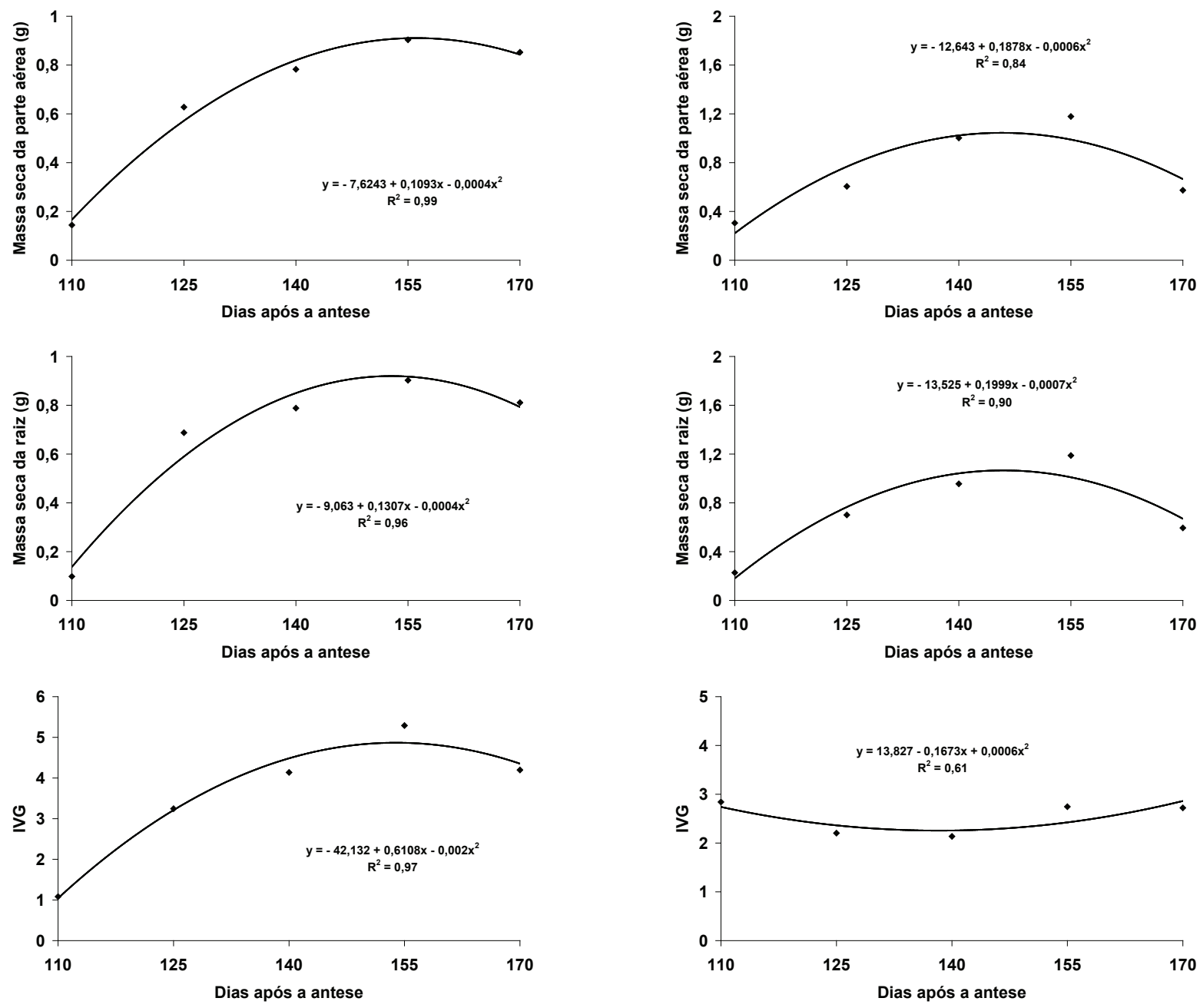

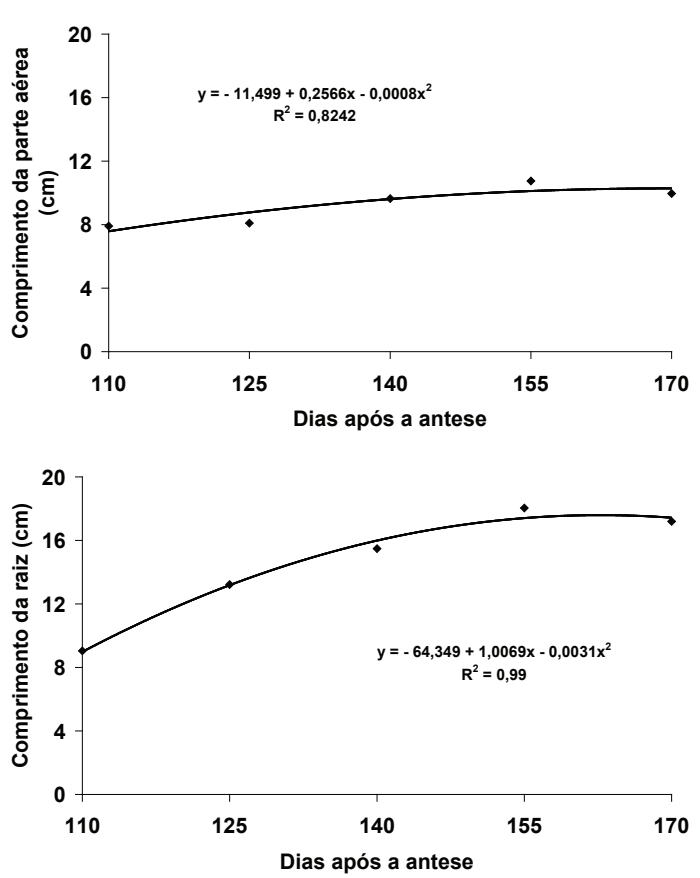

Fonte: Elaboração dos autores.

A primeira contagem de germinação no ano de 2007 apresentou comportamento similar à germinação, atingindo a máxima porcentagem (96\%) aos 145 dias, seguida de uma redução gradual ao longo da maturação do fruto (Figura 5 A2). No ano seguinte, a primeira contagem apresentou comportamento inverso, com valor máximo aos 110 dias, na primeira observação, com redução gradual ao longo do período de observação (Figura 5 B2), os anos observados este parâmetro ajustou-se ao modelo quadrático de regressão.

Quanto à massa seca da parte aérea de plântulas em 2007 observa-se que houve acúmulo gradativo a partir de 110 dias, alcançando o máximo aos 137 DAA (Figura 6 A1). No ano seguinte aos 163 DAA foi alcançado o valor máximo (Figura 6 B1). Com relação à massa seca das raízes, em 2007 e 2008, os valores ajustaram-se ao modelo quadrático de regressão, atingindo valor máximo aos 156 DAA e 147 DAA, respectivamente (Figuras 6 A2 e B2).

O índice de velocidade de germinação (IVG) apresentou comportamento similar ao parâmetro da primeira contagem da germinação, com valores
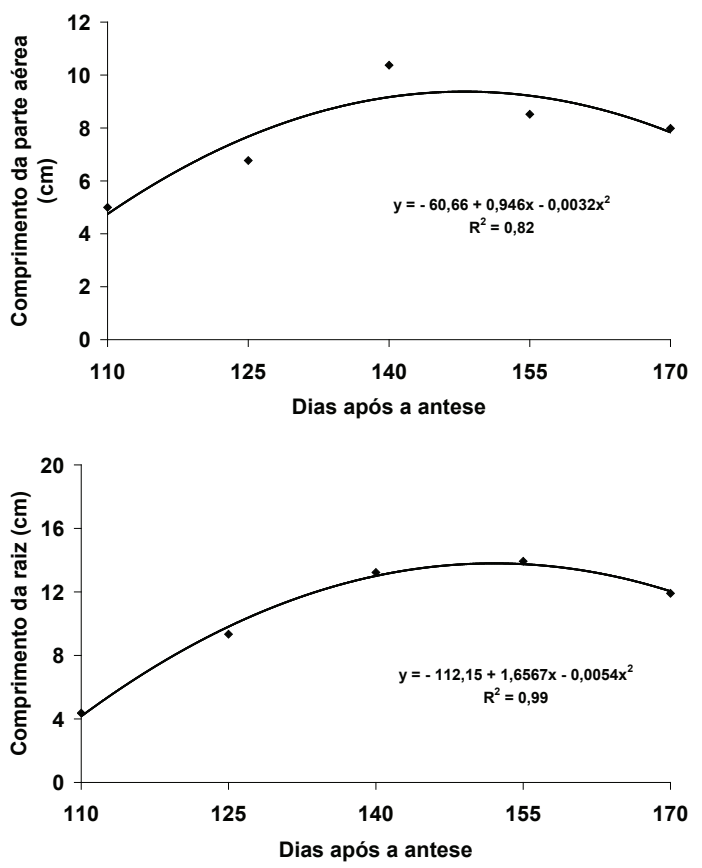

crescentes ao longo do tempo de observação, até um máximo aos 152 dias, quando passou a decrescer (Figura 6 A3). No ano seguinte o comportamento foi inverso (Figura 6 B3).

Os valores para comprimento da parte aérea, em 2007, ajustaram-se ao modelo linear de regressão, com valores crescentes ao longo do período de observação. No ano seguinte, os valores ajustaramse ao modelo quadrático, com valores máximos aos 147 DAA (Figura 6 A4 e B4). O comprimento da raiz, nos dois anos observados, ajustou-se ao modelo quadrático de regressão, com valores máximos aos 147 e153 dias após a antese (Figura 6 A5 e B5).

\section{Discussão}

Os processos fenológicos de floração e frutificação observados nos diferentes indivíduos de Inga striata apresentaram variações no período inicial e de duração nos dois anos de observação, sendo 93 dias de frutificação no primeiro ano e 142 dias para o segundo ano. Este fato possivelmente esteja relacionado com fatores climáticos locais 
(Figura 1), principalmente a temperatura que apresentou-se mais elevada no primeiro ano e mais amena no segundo, e a precipitação, que foi o fator que mais diferiu entre nos dois anos, variando entre 20 a $50 \mathrm{~mm}$ no primeiro ano, e no segundo, entre 53 a $97 \mathrm{~mm}$. A menor disponibilidade de água pode ter acelerado a floração no primeiro ano e atrasado esse evento no ano posterior. Fatores genéticos e ecológicos podem adiantar ou atrasar o processo de maturação das sementes, e a temperatura tem sido citada como um dos fatores mais importantes na aceleração ou retardamento desse processo (AGUIAR; PIÑA-RODRIGUES; FIGLIOLIA, 1993. Em Inga uruguensis foi constatado desuniformidade no florescimento e uma pequena diferença no período de maturação, com duração de 122 e 108 dias de frutificação nos dois anos consecutivos (FIGLIOLIA; KAGEYAMA, 1994).

Variações na fenologia, assincronia de abertura floral e de polinização e maturação diferencial das sementes na mesma planta, contribuem para que a dispersão não ocorra em um único momento. Tais fatos, em sementes recalcitrantes, como em espécies de Inga, aumentam as chances de sobrevivência a eventos ambientais desfavoráveis e a distribuição da germinação no tempo se dar por meio da ampliação do período de florescimento e frutificação da espécie (BRANCALION; MARCOS FILHO, 2008).

Alterações na coloração de frutos durante o processo de maturação foram registradas em algumas espécies de Fabaceae como em I. uruguensis Hook. et Arn (FIGLIOLIA; KAGEYAMA, 1994), Mimosa caesalpiniifolia Benth.(ALVES et al., 2005), Machaerium brasiliense Vogel (GUIMARÃES; BARBOSA, 2007), Mucuna aterrima (Piper Tracy) Holland) (NAKAGAWA et al., 2007) Piptadenia gonoacantha (Mart.) Macbr.(CHITARRA et al., 2008), Piptadenia viridiflora (Kunth.) Benth. (PESSOA et al., 2010).

A cor do fruto nem sempre apresenta referência na identificação prática do estágio de colheita da espécie, como por exemplo, em Tabebuia chrysotricha (Mart. ex DC.) Standl.,conhecida como ipê-amarelo-cascudo que em todos os estágios de colheita, os frutos foram mareloamarronzados (MARTINS; MARTINELLISENEME; NAKAGAWA, 2008). Entretanto, em Piptadenia gonoacantha (Mart.)Macbr. sementes de frutos verdes e verde-marrons recém-colhidos apresentaram maior índice de germinação (CHITARRA et al., 2008).

As sementes colhidas aos 95 DAA, nos dois anos de maturação não emitiram radícula nem produziram plântulas normais no teste de germinação por encontrarem-se fisiologicamente imaturas, onde ao final do teste de germinação registrou-se alta porcentagem de sementes mortas. Comportamento semelhante foi registrado para as sementes de Tabebuia impetiginosa (GEMAQUE; VIDE; FARIA, 2002), as quais aos 60 dias após a antese encontravam-se imaturas, atingindo $100 \%$ de mortalidade.

O fato do tamanho médio dos frutos apresentarem valores máximos aos 140 dias no ano de 2007 e aos 170 dias no ano seguinte, sugere que as oscilações nas dimensões devem estar relacionadas tanto aos fatores climáticos como a variação no sincronismo do processo de frutificação observado entre os indivíduos durante o experimento. As dimensões dos frutos não foram consideradas um índice visual eficaz para auxiliar na determinação do ponto de maturidade fisiológica, dada a grande variação observada dos processos fenológicos dessa espécie. Esses dados corroboram com a interpretação de Piña-Rodrigues e Aguiar (1993), a qual considera que o tamanho dos frutos não tem se revelado um bom índice para muitas espécies, visto a plasticidade dessa característica.

Resultados semelhantes foram referidos para I. uruguensis Hook. et Arn., em que a grande variabilidade observada para o tamanho dos frutos inviabilizou sua utilização como índice de maturação das sementes. O tamanho dos frutos não foi um bom parâmetro para auxiliar na determinação 
do ponto de maturidade fisiológica em sementes de Copaifera langsdorffii (BORGES; BORGES, 1979) e Mimosa caesalpiniifolia Benth. (ALVES et al., 2005), porém, divergente dos dados da maturação de Torresia acreana Ducke (FIRMINO; SANTOS; SANTOS FILHO, 1996), Tibouchina granulosa Cogn. (LOPES; DIAS; PEREIRA, 2005) e Machaerium brasiliense Vogel (GUIMARÃES; BARBOSA, 2007), Mucuna aterrima (Piper Tracy) Holland) (NAKAGAWA et al., 2007) nos quais o tamanho dos frutos foi revelado bom indicador do ponto de maturidade fisiológica. Nesse sentido, Carvalho et al. (2008), afirmaram que nos estádios iniciais do processo de maturação o aumento das dimensões características dos frutos e sementes é comum, em razão do acúmulo de matéria seca e a menor perda de água.

No primeiro ano de maturação as sementes atingiram valores máximos de comprimento, largura e espessura antes do seu ponto de maturidade, o qual foi alcançado entre 166 e 170 dias com o máximo de massa seca e o menor teor de água. No ano seguinte coincidiram os valores máximos de tamanho das sementes e massa seca, embora o valor mínimo do teor de água tenha ocorrido aos 155 dias, sendo que aos 170 dias após a antese o teor de água das sementes foi 49,91\%. Pode-se inferir que as sementes atingiram o máximo de tamanho em curto período de tempo em relação ao período total de maturação e que, embora os tamanhos máximos tenham se antecipado ao ponto de maturidade no primeiro ano, no ano seguinte observa-se uma relação entre o tamanho da semente e o ponto de maturidade. No presente trabalho, considerase o tamanho da semente um índice visual eficaz para indicar o ponto de maturidade fisiológica das mesmas.

Como aos 155 dias as sementes atingiram o menor teor de água e o máximo acúmulo de massa seca, nesse ano de 2008, o máximo de germinação e vigor ocorreu quando as sementes ainda tinham o mínimo teor de água, ou seja, o ponto de maturidade ocorreu aos 155 dias após a antese. Pela tendência nos dois anos de estudo, o teor de água das sementes pode ser considerado um bom índice para predizer seu ponto de maturidade fisiológica, tendo em vista que os valores mínimos foram atingidos quando as sementes estavam com o máximo poder germinativo. Resultados semelhantes foram obtidos para semente de Copaifera langsdorffii Desf. (BARBOSA; AGUIAR; SANTOS, 1992), I. uruguensis Hook et Arn (FIGLIOLIA; KAGEYAMA, 1994); e Erythrina variegata L. (MATHEUS; LOPES; CORRÊEA, 2011).

Os valores do teor de água das sementes de I. striata, por ocasião de sua maturidade são característicos da espécie e fundamental para sua sobrevivência. Esse comportamento pode ser um mecanismo de adaptação, no sentido de assegurar a perpetuação da espécie, uma vez que suas sementes são de baixa longevidade por serem sensíveis a reduções do teor de água abaixo de $23 \%$ (sementes recalcitrantes), necessitando germinar prontamente ao se desligarem da planta.

Esses dados corroboram com os que foram detectados em sementes de I. uruguensis, nas quais houve alta percentagem de sementes mortas aos 91 e 100 dias, germinando apenas aos 114 dias, com valores máximos aos 142 dias do florescimento (FIGLIOLIA; KAGEYAMA, 1994).

O teor de água das sementes oriundas de frutos verdes nos dois anos de maturação atingiu valores mais baixos aos 140 dias após a antese (Figura 4 A1 e B1) e, pela tendência de redução lenta no estudo de 2007, o teor de água das sementes pode ser considerado um bom índice para predizer seu ponto de maturidade fisiológica, tendo em vista que os valores menores foram atingidos quando as sementes apresentavam o máximo poder germinativo (Figura 5 A1), embora no estudo de 2008 o máximo poder germinativo foi constatado aos 125 dias após a antese (Figura 5 B1). Desse modo constata-se, que as sementes atingiram a maturidade com teores de água elevados, contrastando com o comportamento observado em diferentes espécies nativas, nas quais 
há uma brusca queda no teor de água durante o processo de maturação, a exemplo de Dalbergia nigra (MARTINS; SILVA 1997), mucuna-preta (NAKAGAWA; CAVARIANI; ZUCARELI, 2005), mucuna-preta (NAKAGAWA; CAVARIANI; ZUCARELI, 2005) Mimosa caesalpiniifolia Benth. (ALVES et al., 2005), Caesalpinia echinata Lam. (AGUIAR et al., 2007). No entanto, Bilia, MarcosFilho e Novembre (1999) observaram que o teor crítico de água em sementes de Inga uruguensis ocorreu em torno de $35 \%$, e o letal entre 21 e $22 \%$, o mesmo verificou Bacchi (1961) para sementes de Inga edulis.

A ocorrência do elevado teor de água em sementes de $I$. striata por ocasião da maturidade, também foi observado em I. uruguensis, uma espécie predominante de locais úmidos (FIGLIOLIA; KAGEYAMA, 1994). Possivelmente, o elevado conteúdo de umidade nas sementes de Inga é característico das próprias espécies e fundamental para a sobrevivência, ocasionando muitas vezes a germinação dentro do fruto, podendo ser uma estratégia de sobrevivência das mesmas, uma vez que são sementes recalcitrantes (BILIA; BARBEDO; MARCOS FILHO, 2003).

Com os dados de germinação (Figura 5 A1) e vigor (massa seca de parte aérea e da raiz) nos dois anos consecutivos (Figuras 6 A1, A2 e B1, B2) constatou-se uma tendência de que aos 155 dias da antese a semente atinge sua máxima qualidade fisiológica. Vários autores revelam que as sementes atingem sua máxima qualidade fisiológica quando estão com o máximo poder germinativo e vigor (POPINIGIS, 1997; CARVALHO; NAKAGAWA, 2000; MARCOS FILHO, 2005). Esses resultados foram constatados em sementes de Mimosa caesalpiniifolia (ALVES et al., 2005), Tamarindus indica L., (GURJÃO et al., 2006) e Caesalpinia echinata Lam. (AGUIAR et al., 2007).

Com relação ao índice de velocidade de germinação, comprimento e massa seca da parte aérea (Figuras 6 A3, A4 e A5) raiz principal e plântulas (Figuras 6 A1 e A2), no ano de 2007, essas variáveis alcançaram valores máximos estimados aos 155 DAA, os quais coincidiram com o máximo acúmulo de massa seca e menor teor de água das sementes. Pode-se constatar assim, que após esse período, as sementes atingem seu ponto de maturidade, ocorrendo modificações bioquímicas e fisiológicas, conforme enfatiza Popinigis (1997). A utilização do acúmulo de massa seca como índice de maturação também foi eficaz para a determinação do ponto de maturidade fisiológica de sementes de Dalbergia nigra (Vell.) Fr. All. ex Benth. (MARTINS; SILVA, 1997) e Erythrina variegata (MATHEUS; LOPES; CORRÊA, 2011).

\section{Conclusões}

A maturidade fisiológica das sementes foi atingida aos 146 a 166 dias após a antese no primeiro ano e aos 155 dias no segundo ano, períodos em que apresentaram o menor teor de água, máximo acúmulo de massa seca e poder germinativo;

O tamanho, teor de água, massa seca da semente, capacidade germinativa e ainda a massa seca da parte aérea da plântula, foram os parâmetros que melhor determinaram a maturação fisiológica das sementes de I. striata.

\section{Referências}

AGUIAR, F. F. A.; PINTO, M. M.; TAVARES, A. R.; KANASHIRO, S. Maturação de frutos de Caesalpinia echinata Lam., pau-brasil. Revista Árvore, Viçosa, v. 31, n. 1, p. 1-6, 2007.

AGUIAR, I. B.; PIÑA-RODRIGUES, F. C. M.; FIGLIOLIA, M. B. Sementes florestais tropicais. Brasília: ABRATES, 1993. 360 p.

ALVES, E. U.; SADER, R.; BRUNO, R. L. A.; ALVES, A. U. Maturação fisiológica de sementes de sabiá. Revista Brasileira de Sementes, Viçosa, v. 27, n. 1, p. 1-8, 2005.

ANDRÉO, Y.; NAKAGAWA, J.; BARBEDO, C. J. Mobilização de água e conservação da viabilidade de embriões de sementes recalcitrantes de ingá (Inga vera Willd. subsp. affinis (DC.) T. D. Pennington). Revista Brasileira de Botânica, São Paulo, v. 29, n. 2, p. 309318, 2006. 
BACCHI, O. Estudos sobre a conservação de sementes. IX- Ingá. Boletim Técnico do Instituto Agronômico do Estado de São Paulo. Bragantia, Campinas, v. 20, n. 35, p. 805-814, 1961.

BARBEDO, C. J.; BILIA, D. A. C. Germinação de sementes e desenvolvimento de plântulas de Inga uruguensis Hook. \& Arn. em função da remoção de sarcotesta. Informativo Abrates, Curitiba, v. 7, n. 3, p. 54-56, 1997.

BARBEDO, C. J.; CÍCERO, S. M. Utilização do teste de condutividade elétrica para previsão do potencial germinativo de sementes de ingá. Scientia Agrícola, Piracicaba, v. 55, n. 2, p. 249-359, 1998.

BARBOSA, J. M.; AGUIAR, I. B.; SANTOS, S. R. G. Maturação de sementes de Copaifera langsdorffii Desf. Revista do Instituto Florestal, São Paulo, v. 4, p. 665674, 1992.

BILIA, D. A. C.; BARBEDO, C. J.; MARCOS FILHO, J. Ingá: uma espécie importante para recomposição vegetal em florestas ripárias, com sementes interessantes para a ciência. Informativo Abrates, Londrina, v. 13, n. 1-2, p. 26-30, 2003.

BILIA, D. A. C., MARCOS-FILHO, J.; NOVEMBRE, A. D. C. L. Desiccation tolerance and seed storability of Inga uruguensis (Hook. et Arn.). Seed Science and Technology, Zurich, v. 27, n. 1, p. 77-89, 1999.

Conservação da qualidade fisiológica de sementes de Ingá uruguensis. Revista Brasileira de Sementes, Brasília, v. 20, n. 1, p. 48-54, 1998.

BONJOVANI, M. R.; BARBEDO, C. J. Sementes recalcitrantes: intolerantes a baixas temperaturas? Embriões recalcitrantes de Inga vera Willd. subsp. affinis (DC.) T. D. Penn. toleram temperatura sub-zero. Revista Brasileira de Botânica, São Paulo, v. 31, n. 2, p. 345-356, 2008.

BORGES, E. E. L.; BORGES, C. G. Germinação de sementes de Copaifera langsdorffii Desf. provenientes de frutos com diferentes graus de maturação. Revista brasileira de sementes, Brasília, v. 1, n. 3, p. 45-7, 1979.

BRANCALION, P. H. S.; MARCOS FILHO, J. Distribuição da germinação no tempo: causas e importância para a sobrevivência das plantas em ambientes naturais. Informativo Abrates, Brasília, v. 18, n. 1-2-3, p. 11-17, 2008.

BRASIL, Ministério da Agricultura e da Reforma Agrária. Regras para análise de sementes. Secretaria de Defesa Agropecuária. Brasília: MAPA/ACS, 2009. 399 p.
CARVALHO, M. L. M.; NERY, M. C.; OLIVEIRA, L. M. de; HILHORST, H. W. M.; GUIMARÃES, R. M. Morphophysiological development of Tabeluia serratifolia. Vahl Nich. Scientia Agricola, Piracicaba, v. 65, n. 6, p. 643-651, 2008.

CARVALHO, N. M.; NAKAGAWA, J. Armazenamento. In: CARVALHO, N. M.; NAKAGAWA, J. Sementes: ciência, tecnologia e produção. Jaboticabal: FUNEP, 2000. p. 485-521.

CARVALHO, N. M.; SOUZA FILHO, J. F.; GRAZIANO, T. T.; AGUIAR, I. B. Maturação fisiológica de sementes de amendoim-do-campo. Revista Brasileira de Sementes, Brasília, n. 2, p. 23-27, 1980.

CHITARRA, J. F.; MORI, E. S.; NAKAGAWA, J.; OHTO, C. T.; PINTO, C. S.; FERNANDES K. H. P. Época de colheita de sementes de pau-jacaré Piptadenia gonoacantha (Mart.) Macbr. Revista Cientifica Eletrônica de Engenharia Florestal, Garça, ano 7, n. 12, p. 1-12, 2008.

CORVELLO, W. B. V.; VILLELA, F. A.; NEDEL, J. L.; PESKE, S. T. Maturação fisiológica de sementes de cedro (Cedrela fissilis Vell.). Revista Brasileira de Sementes, Pelotas, v. 21, n. 2, p. 23-27, 1999.

FALCÃO, M. A.; CLEMENT, C. R. Fenologia e produtividade do ingá-cipó (Inga edulis) na Amazônia Central. Acta Amazônica, Binagri, v. 30. n. 2, p. 173-180, 2000.

FARIA, J. M. R.; DAVIDE, L. C.; SILVA, E. A. A.; DAVIDE, A. C.; PEREIRA, R. C.; LAMMEREN, A. M.; HILHORST, H. W. M. Physiological and cytological aspects of Inga vera subsp. affinis embryos during storage. Brazilian Journal Plant Physiology, Londrina, v. 18, n. 4, p. 503-513, 2006.

FIGLIOLIA, M. B.; KAGEYAMA, P. Y. Maturação de sementes de Inga uruguensis Hokk. et Arn. em floresta ripária do rio Mogi Guaçu, município de Moji Guaçu, SP. Revista do Instituto Florestal, São Paulo, v. 6, p. 1352, 1994.

FIRMINO, J. L.; SANTOS, D. S. B.; SANTOS FILHO, B. G. Características físicas e fisiológicas de semente de cerejeira (Torresia acreana Ducke) quando as sementes foram coletadas do chão ou do interior dos frutos. Revista Brasileira de Sementes, Brasília, v. 18, n. 1, p. 28-32, 1996.

GARCIA, F. C. P. Relações sistemáticas e fitogeográficas do gênero Inga Miller (Leguminosae. Mimosoideae. Ingeae) nas florestas da costa Sul e Sudeste do Brasil. 1998. Tese (Doutorado em Ciências Biológicas) Universidade Estadual Paulista, São Paulo. 
GEMAQUE, R. C. R.; VIDE, A. C.; FARIA, J. M. R. Indicadores de maturidade fisiológica de sementes de ipê-roxo (Tabebuia impetiginosa (Mart.) Standl.). Cerne, Lavras, v. 8, n. 2, p. 84-91, 2002.

GUIMARÃES, D. M.; BARBOSA, J. M. Coloração dos frutos como índice de maturação para sementes de Machaerium brasiliense vogel (Leguminosae Fabaceae). Revista Brasileira de Biociências, Porto Alegre, v. 5, p. 567-569, 2007. Suplemento 2.

GURJÃO, K. C. O.; BRUNO, R. L. A.; ALMEIDA, F. A. C.; PEREIRA, W. E.; BRUNO, G. B. Desenvolvimento de frutos e sementes de tamarindo. Revista Brasileira de Fruticultura, Cruz das Almas, v. 28, n. 3, p. 351-354, 2006.

LOPES, C. A.; DIAS, P. C.; PEREIRA, M. D. Maturação fisiológica de sementes de quaresmeira. Pesquisa Agropecuária Brasileira, Brasília, v. 40, n. 8, p. 811-816, 2005.

MAGUIRE, J. D. Speed of germination in selection and evaluation for seedling emergence and vigor. Crop Science, Madison, v. 2, n. 1, p. 176-177, 1962.

MALAVASI, M. Germinação de sementes. In: PIÑARODRIGUES, F. C. M. (Coord.). Manual de análise de sementes florestais. Campinas: Fundação Cargill, 1998. p. 25-40.

MARCOS FILHO, J. M. Fisiologia de sementes de plantas cultivadas. Piracicaba: FEALQ, 2005. 495 p.

MARTINS, C. C.; MARTINELLI-SENEME, A.; NAKAGAWA, J. Estágio de colheita e substrato para o teste de germinação de sementes de ipê (Tabebuia chrysotricha (Mart. ex DC.) Standl.) Revista Árvore, Viçosa, v. 32, n. 1, p. 27-32, 2008.

MARTINS, S. V.; SILVA, D. D. Maturação e época de colheita de sementes de Dalbergia nigra (Vell.) Fr. All. ex Benth. Revista Brasileira de Sementes, Brasília, v. 19, n. 1, p. 96-99, 1997.
MATHEUS, M. T.; LOPES, J. C.; CORREAA, N. B. Maturação fisiológica de sementes de Erythrina variegata L. Ciência Florestal, Santa Maria, v. 21, n. 4, p. 619-627, 2011.

NAKAGAWA, J.; CAVARIANI, C.; ZUCARELI, C. Maturação, formas de secagem e qualidade de sementes de mucuna-preta. Revista Brasileira de Sementes, Brasília, v. 27, n. 1, p. 45-53, 2005.

NAKAGAWA, J.; ZUCARELI, C.; CAVARIANI, C.; GASPAR-OLIVEIRA, C. Maturação de sementes de mucunã-preta. Bioscience Journal, Uberlândia, v. 23, n. 1, p. 41-47, 2007.

PENNINGTON, T. D. The genus inga: botany. Kew: Royal Botanic Gardens, 1997. 844 p.

PESSOA, S. C.; MATSUMOTO, S. N.; MORAIS, O. N.; VALE, R. S.; LIMA, J. M. Germinação e maturidade fisiológica de sementes de Piptadenia viridiflora (Kunth.) Benth relacionadas a estádios de frutificação e conservação pós-colheita. Revista Árvore, v. 34, n. 4, p. 617-625, 2010.

PIÑA-RODRIGUES, F. C. M.; AGUIAR, I. B. Maturação e dispersão de sementes. In: PIÑA-RODRIGUES, F. C. M.; AGUIAR, I. B.; FIGLIOLIA, M. B. (Coord.). Sementes florestais tropicais. Brasília: ABRATES, 1993. p. 215-274.

POPINIGIS, F. Fisiologia da semente. Brasília, DF: AGIPLAN, 1997. 287 p.

PRITCHARD, H. W.; HAYE, A. J. W.; STEADMAN, K. J. A comparative study of seed viability in Inga species: desiccation tolerance in relation to the physical characteristics and chemical composition of the embryo. Seed Science and Technology, Zurick, v. 23, n. 1, p. 85100, 1995.

VIEIRA, R. D.; CARVALHO, N. M. Testes de vigor em sementes. Jaboticabal: FANEP/UNESP. 1994. 164 p. 
